Macedonian Pharmaceutical Bulletin, 66 (Suppl 1) 103 - 104 (2020)

Online ISSN 1857 - 8969

UDC: 615.276 .014 .2

DOI: 10.33320/maced.pharm.bull.2020.66.03.051

Short communication

\title{
Characterization of chitosan/xanthan gum polyelectrolyte complexes as carriers for ibuprofen: influence of drug encapsulation procedure on complex formation
}

\author{
Ana Ćirić*, Ljiljana Đekić \\ Department of Pharmaceutical Technology and Cosmetology, Vojvode Stepe 450, 11221 Belgrade, Serbia
}

\section{Introduction}

Ibuprofen (IBU) is commonly used non-steroidal anti-inflammatory drug. It is a weak acid ( $\mathrm{pKa} \sim 4.5)$ with low $\mathrm{pH}$ dependent aqueous solubility (46 $\mu \mathrm{g} / \mathrm{mL}$ at $\mathrm{pH} 1.5$ and $>300 \mu \mathrm{g} / \mathrm{mL}$ at $\mathrm{pH}>7$, at 25 $\left.{ }^{\circ} \mathrm{C}\right)$. The most commonly used oral dose is $200-600$ $\mathrm{mg} / 6 \mathrm{~h}$. Drug solubility, which affects the dissolution and absorption from the formulation is a common problem in developing efficient formulation for oral IBU delivery (Ćirić et al., 2020; Irvine et al., 2018).

Chitosan $(\mathrm{CH})$ and xanthan gum (XG) polyelectrolyte complexes (PECs) already demonstrated improved drug solubility, permeability, $\mathrm{pH}$ sensitivity and controlled drug release. Polycationic $\mathrm{CH}$ can interact electrostatically with negatively charged compounds (Sogias et al., 2012), such as XG, for the development of PEC-based drug carriers.

IBU encapsulation procedure could influence the drug-polymer interactions and the PECs formation. The aim of this study was to evaluate the influence of IBU encapsulation procedure on the formation and properties of $\mathrm{CH} / \mathrm{XG}$ PECs as drug carriers.

\section{Materials and methods}

Three different procedures of IBU (BASF, Germany) encapsulation were performed. In the procedure A, IBU was mixed with formed PEC hydrogel consisting of medium molecular weight $\mathrm{CH}$ (Sigma Aldrich, USA) and XG (Jungbunzlauer, Switzerland) (4.6A). In the procedure B, IBU was dispersed in the $\mathrm{XG}$ solution before mixing with the $\mathrm{CH}$ solution and PEC formation (4.6B). In the procedure $\mathrm{C}$, IBU was added into the aqueous medium after the complexing of $\mathrm{CH}$ and $\mathrm{XG}$ and allowed to diffuse into the PEC (4.6C). The concentration of both polymers in the aqueous solutions was $0.65 \% \mathrm{w} / \mathrm{v}$, and their volume ratio $1: 1$. The $\mathrm{pH}$ of $\mathrm{CH}$ solutions was adjusted to 4.6 with acetic acid. Mixing was performed on laboratory propeller mixer RZR 2020 (Heidolph, Germany). IBU-to-polymers mass ratio was 1:1.

The evaluation of PECs formation and the strength of interactions between the polymers and IBU was done by $\mathrm{pH}$ (HI 9321, Hanna Instruments, USA), conductivity (CDM 230, Radiometer, Denmark) and rheological measurements (Rheolab MC 120, Paar Physica, Austria) by increasing the shear rate from 0 to $100 \mathrm{~s}^{-1}$ and back to $0 \mathrm{~s}^{-1}$ at $20 \pm 0.2{ }^{\circ} \mathrm{C}$, in triplicate.

PEC hydrogels were dried under ambient conditions, grinded and sieved. Then, the yield $(\% \mathrm{Y})$, the IBU encapsulation efficiency (\%EE) and the drug loading (\%DL) were calculated. The total amount of $\mathrm{CH}, \mathrm{XG}$ and IBU, the initial amount of IBU used for PEC preparation and the IBU/polymers

\footnotetext{
* ana.ciric@ @ pharmacy.bg.ac.rs
} 
ratio were considered $100 \%$ for $\% \mathrm{Y}, \% \mathrm{EE}$ and $\% \mathrm{DL}$, respectively. The calculation of $\% \mathrm{EE}$ and \%DL: $20 \mathrm{mg}$ of each PEC was dissolved in $100 \mathrm{ml}$ of methanol/phosphate buffer $\mathrm{pH} 7.2(80: 20 \mathrm{~V} / \mathrm{V})$ by sonication (Sonorex RK1024, Bandelin, Germany). IBU concentration was determined spectrophotometrically at $224 \mathrm{~nm}$ (Evolution 300, Thermo Scientific, USA).

\section{Results and discussion}

After the complexing of $\mathrm{CH}$ and $\mathrm{XG}$ and the encapsulation of IBU, the $\mathrm{pH}$ values of $4.33 \pm 0.05$ for $4.6 \mathrm{~A}, 4.49 \pm 0.05$ for $4.6 \mathrm{~B}$ and $4.11 \pm 0.03$ for $4.6 \mathrm{C}$ were measured. The lowest $\mathrm{pH}$ of $4.6 \mathrm{C}$ can be explained by the diffusion of hydrogen ions into the hydrogel from the PEC preparation medium, due to IBU dissociation. The highest $\mathrm{pH}$ for $4.6 \mathrm{~B}$ could be explained by the dispersion of IBU in XG solution at high drug concentration. That suppresses its dissociation, resulting in lower concentrations of hydrogen ions into the hydrogel. The ionization ability of IBU, responsible for its non-covalent interactions with $\mathrm{CH}$ and $\mathrm{XG}$, may accelerate the dissolution of this crystalline drug by partial disruption of its crystal lattice, which could potentially influence the release kinetics of IBU from PEC-based carriers (Sogias et al., 2012).

The conductivity decreased during the formation of PECs, confirming the establishment of interactions between the polymers and IBU. The final conductivity of $4.6 \mathrm{~A}$ was $920 \pm 11 \mu \mathrm{S} / \mathrm{cm}$, of $4.6 \mathrm{~B}$ was $615 \pm 3 \mu \mathrm{S} / \mathrm{cm}$, and of $4.6 \mathrm{C} 833 \pm 67 \mu \mathrm{S} / \mathrm{cm}$. The differences between the samples were expected since only free ions are responsible for the conductivity of samples (Ćirić et al., 2020).

All PECs showed pseudoplastic flow behavior with thixotropy. Thixotropy was evaluated based on the hysteresis area $(\mathrm{H})$ values. The highest value of $1019.10 \pm 297.01 \mathrm{~Pa} / \mathrm{s}$ was detected for $4.6 \mathrm{~B}$, while the lowest, $68.20 \pm 47.39 \mathrm{~Pa} / \mathrm{s}$, was measured for 4.6A. The $\mathrm{H}$ of $4.6 \mathrm{C}$ was $784.06 \pm 143.63 \mathrm{~Pa} / \mathrm{s}$. Higher $\mathrm{H}$ values are correlated with stronger interactions between IBU and polymers (Ćirić et al., 2020; Djekic et al., 2016). The strength of the interactions was also evaluated by measuring the apparent viscosity (maximal at $11.1 \mathrm{~s}^{-1}-\eta_{\max }$, and minimal at $100 \mathrm{~s}^{-1}-\eta_{\min }$ ) of PECs. The highest $\eta_{\max }$ was measured for $4.6 \mathrm{~B}(4.97 \pm 0.43 \mathrm{~Pa} \cdot \mathrm{s})$, and the lowest for 4.6A $(3.92 \pm 0.36 \mathrm{~Pa} \cdot \mathrm{s})$. The $\eta_{\max }$ for $4.6 \mathrm{C}$ was $4.30 \pm 0.23 \mathrm{~Pa} \cdot \mathrm{s}$. The $\eta_{\min }$ for all samples was $0.64 \pm 0.08 \mathrm{~Pa} \cdot \mathrm{s}$. These results are in accordance both with thixotropy and the conductivity of the samples.

The highest $\% \mathrm{Y}$ and $\% \mathrm{EE}$ had $4.6 \mathrm{~B}$ (54.14 $\pm 3.14 \%$ and $59.05 \pm 3.14 \%$, respectively), and the lowest $4.6 \mathrm{C}(18.70 \pm 4.23 \%$ and $0.89 \pm 0.05 \%$, respectively). For $4.6 \mathrm{~A}, \% \mathrm{Y}$ was $48.04 \pm 2.08 \%$, and $\%$ EE $53.19 \pm 3.07 \%$. \%DL $\sim 50 \%$ for $4.6 \mathrm{~A}$ and $4.6 \mathrm{~B}$ and $2.5 \%$ for $4.6 \mathrm{C}$ indicated that the PEC $4.6 \mathrm{~B}$ resulted in the best characteristics as a carrier of poorly soluble, highly dosed drug, such as IBU.

\section{Conclusion}

IBU encapsulation by dispersion in the $\mathrm{XG}$ solution before mixing with the $\mathrm{CH}$ solution (PEC formation) could be considered optimal to prepare PECs as promising drug carriers with strongest interpolymer interactions, the highest $\% \mathrm{Y}$, and \%EE.

\section{Acknowledgement}

This work was supported by the Ministry of Education, Science and Technological Development of the Republic of Serbia.

\section{References}

Ćirić, A., Medarević, Đ., Čalija, B., Dobričić, V., Mitrić, M., Djekic, L., 2020. Study of chitosan/xanthan gum polyelectrolyte complexes formation, solid state and influence on ibuprofen release kinetics. Int. J. Biol. Macromol. 148, 942-955.

Djekic, L., Martinović, M., Stepanović-Petrović, R., Micov, A., Tomić, M., Primorac, M., 2016. Formulation of hydrogel-thickened nonionic microemulsions with enhanced percutaneous delivery of ibuprofen assessed in vivo in rats. Eur. J. Pharm. Sci. 92, 255-265.

Irvine, J., Afrose, A., Islam, N., 2018. Formulation and delivery strategies of ibuprofen: challenges and opportunities. Drug Dev. Ind. Pharm. 44, 173-183.

Sogias, I.A., Williams, A.C., Khutoryanskiy, V.V., 2012. Chitosan-based mucoadhesive tablets for oral delivery of ibuprofen. Int. J. Pharm. 436, 602-610.

Maced. Pharm. Bull. 66 (Suppl 1) 103 - 104 (2020) 